\title{
Analysis on Regional Difference of Inclusive Green Development in China
}

\author{
Shen Yang \\ Jiangxi Institute of economic development, Jiangxi Normal University, Nanchang, Jiangxi, China \\ 906774145@qq.com
}

\begin{abstract}
At present, China's economic aggregate is constantly increasing. Social and environmental issues are receiving more and more attention. Economic sustainable development, social equity and environmental protection have become the tings which the development should contain. Inclusive Green development has emerged in this context. In this paper, the Top-sis entropy method is used to measure and summarize the inclusive green development level of China's provinces. Furthermore, the spatial distribution characteristics of inclusive green development in China in recent years are analyzed by using ArcGIS technology from the geographical perspective. The spatial distribution characteristics of inclusive green development in China are highly concentrated. The uneven trend of development distribution has been alleviated and the trend of distribution spread from coastal to inland, especially the spatial spillover effect of Yangtze River Delta Economic Zone inclusive green development. This paper reveals the general law of inclusive green development in China, and provides experience for follow-up research.
\end{abstract}

Keywords: Inclusive Green development, regional differences, spatial characteristics

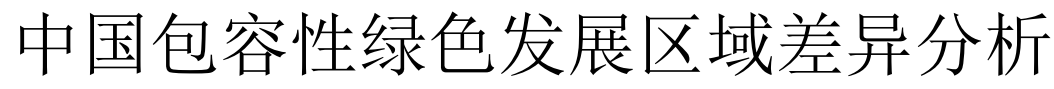

$$
\text { 沈炀 }
$$

江西师范大学江西经济发展研究院, 南昌, 江西, 中国 906774145@qq.com

\section{摘要}

当前, 我国经济总量不断提升, 社会问题和环境问题越来越收到关注, 经济可持续发展、社会公平、环境保护 成为新时代发展的应有之义。包容性绿色发展即是在此背景下应运而生。文章通过运用 Top-sis 熵值法对我国 省域包容性绿色发展水平进行测度与总结。进一步，运用 ArcGIS 技术从地理视角分析了近年来我国包容性绿 色发展的空间分布特征: 我国包容性绿色发展近年来呈现出高度集中的空间分布特征，但发展分布的不均衡趋 势有所缓解, 分布趋势由沿海向内陆扩散, 特别是长三角地区包容性绿色发展的空间溢出效应显著。以此揭示 我国包容性绿色发展的一般规律，为后续研究提供经验借鉴。

关键词: 包容性绿色发展，区域差异，空间特征

\section{1. 前言}

当前, 我国社会主要矛盾已经转变, 不平衡不充 分的发展无法满足人民日渐增加的需求。这要求我国 在推进经济社会进一步发展时, 着力解决发展不平衡 不充分的问题, 深入贯彻科学发展观, 落实新的发展 理念，提升发展质量，缩小人民在经济、政治、文化、
社会、生态等方面的福利差距，推动经济社会向更公 平、更高效、更绿色的方向发展。促进经济社会包容 性绿色发展符合我国社会主要矛盾转变的基本要求, 既是我国经济社会高质量发展的目的也是手段。

\section{2. 文献综述}

当前, 关于包容性绿色发展的研究主要来自两个 
方面，一是包容性绿色发展的本质内涵，二是包容性 绿色发展水平的测度与评价。

包容性绿色发展的概念首先由世界银行于 2012 年提出, 世界银行指出经济快速增长需要具备社会包 容性、绿色性以及可持续性 ${ }^{[1]}$ 。同年, “里约 +20 ” 峰 会正式提出这一概念, 强调绿色经济对传统以效率为 导向的经济模式增加了两个重要维度: 一是强调经济 增长要合理集约的运用自然资本, 即控制在自然资本 的使用边界内; 二是强调经济发展中的 “公平”与 “包 容”。之后, Bouma 和 Berkhout（2015）也提出包容 性绿色发展强调的是绿色、包容性与经济增长之间的 平衡, 以及对经济社会中长期福利的关注 ${ }^{\mathbf{2} 1}$ 。 Slingerland 和 Kessler (2015) 指出包容性绿色发展重 视社会公平和环境可持续性, 致力于改善社会福利 ${ }^{\mathbf{1 3}}$ 。 在国内, 吴武林和周小亮在对包容性绿色发展的研究 中认为包容性绿色发展本质上是一种可持续的发展 模式, 其内涵是经济增长、社会公平、成果共享、生 态保护和资源节约的有机统一 ${ }^{5}$ !。

关于包容性绿色发展水平的测度方法主要是通 过将不同维度的指标值综合成一个评价指数。周小亮 等 (2018) 根据包容性绿色发展的内涵、外延和特征, 从经济发展、社会机会公平、绿色生产消费和生态环 境保护四个视角构建指标体系, 并运用摘值 Top-sis 法测度了中国 1999 至 2015 年省域包容性绿色发展指 数 ${ }^{\mathbf{4} 1}$ 。王宇昕等 (2019) 从经济发展、社会包容、民 生福利和绿色可持续四个维度, 对 2011-2016 年长江 经济带 110 个城市包容性绿色增长的状况展开深入 评价，运用空间计量模型分析其空间格局与演变特 征 ${ }^{61}$ 。

综合现有文献对包容性绿色发展水平指标体系 的构建, 并结合当前五大发展理念, 可以将其归纳为 以下几类: 创新维度、协调维度、绿色维度、开放维 度、共享维度。基于此, 共同构建出我国包容性绿色 增长的综合评价指标体系。

\section{1 创新维度}

创新维度主要包括创新投入、创新产出、创新成 效、创新环境。进一步, 将 R\&D 经费投入强度、R\&D 人员折合全时当量、R\&D 人员比重、有研发活动的企 业占比纳入创新投入指标层, 将技术市场成交额占比、 人均专利拥有量纳入创新产出指标层, 将创新产品贡 献度、创新技术贡献度纳入创新成效指标层, 将有研 发机构企业占比、人均 GDP、劳动力受教育水平纳入 创新环境指标层。

\section{2 协调维度}

协调维度主要包括经济协调、社会协调、区域协 调。进一步, 将二三产业比重、产业结构合理化水平、 产业高级化水平、资本配置效率、劳动配置效率纳入 经济协调指标层, 将城镇化水平、城镇失业情况纳入
社会协调指标层, 将地区发展协调水平、地区消费协 调水平纳入区域协调指标层。

\section{3 绿色维度}

绿色维度主要包括经济可持续和环境可持续。进 一步, 将单位产值能耗、单位产值废水排放、单位产 值硫排放、单位产值化学需氧量排放纳入经济可持续 指标层, 将城市绿化水平、人均公园绿地、垃圾处理 水平、污水处理水平、工业固体废物利用水平纳入环 境可持续指标层。

\section{4 开放维度}

开放维度主要包括对内开放和对外开放。进一步, 将金融机构资金使用水平纳入对内开放指标层, 将外 贸开放度、外资开放度、对外经济合作程度纳入对外 开放指标层。

\section{5 共享维度}

共享维度主要包括收入共享、设施共享、医疗共 享、教育共享。进一步, 将城镇居民人均可支配收入、 农村居民人均可支配收入、城乡协调水平、恩格尔系 数纳入收入共享指标层, 将人均排水管道长度、人均 道路长度、人均道路面积纳入设施共享指标层, 将每 万人卫生技术人员数、医疗卫生机构数、人均医疗机 构床位数纳入医疗共享指标层, 将初中生师比、高中 生师比、小学生师比纳入教育共享指标层。

\section{3. 包容性绿色发展水平测度及区域差异分析}

\section{1 省域包容性绿色发展水平测度}

包容性绿色发展水平的测度, 多利用熵值法构建 不同维度的指标体系，以此衡量不同地区的包容性绿 色发展水平, 测度方法如下:

选取 $\mathrm{n}$ 各地区作为样本、设计 $\mathrm{m}$ 个评价指标, $\mathrm{X}_{\mathrm{ij}}$ 表示第 $i$ 个地区的第 $j$ 个评价指标值 $(i=1,2,3 \ldots \ldots n ; j=1,2,3 \ldots \ldots m)$ 。

(1) 对原始数据进行标准化处理, 使各指标具 有可比性。

(2) 对标准化后的数据进行无量纲化处理, 以 消除物理量的影响, 第 $\mathrm{j}$ 个指标下, 第 $\mathrm{i}$ 个地区的贡 献度为:

$$
\mathrm{p}_{\mathrm{ij}}=\frac{\mathrm{x}_{\mathrm{ij}}^{\prime}}{\sum_{\mathrm{i}=1}^{\mathrm{n}} \mathrm{x}_{\mathrm{ij}}}
$$

（3）计算第 $j$ 个指标的熵值。

$$
\mathrm{e}_{\mathrm{j}}=-\frac{1}{\ln \mathrm{n}} \sum_{\mathrm{i}=1}^{\mathrm{n}} \mathrm{p}_{\mathrm{ij}}\left(\ln \mathrm{p}_{\mathrm{ij}}\right), \quad 0 \leq \mathrm{e}_{\mathrm{j}} \leq 1
$$

（4）计算第 $\mathrm{j}$ 个指标的差异性系数。

$$
\mathrm{g}_{\mathrm{j}}=1-\mathrm{e}_{\mathrm{j}}
$$


（5）计算第 $\mathrm{j}$ 个指标的权重 $w_{\mathrm{j}}$ 。

$$
w_{j}=\frac{g_{j}}{\sum_{i=1}^{m} g_{i}}, j=1,2,3 \ldots m
$$

（6）计算各地区加权得分。

$$
S_{i}^{t}=\sum_{j=1}^{m} w_{j} * x_{i j}^{\prime}
$$

(7) 分别确定正、负理想解 $\mathrm{S}_{j}^{+}$和 $\mathrm{S}_{\mathrm{j}}^{-}$:

$$
\begin{aligned}
& \mathrm{S}_{\mathrm{j}}^{+}=\max \left\{\mathrm{S}_{1}, \mathrm{~S}_{2}, \mathrm{~S}_{3}, \mathrm{~S}_{4} \ldots . \mathrm{S}_{\mathrm{n}}\right\} \\
& \mathrm{S}_{\mathrm{j}}^{-}=\min \left\{\mathrm{S}_{1}, \mathrm{~S}_{2}, \mathrm{~S}_{3}, \mathrm{~S}_{4} \ldots . \mathrm{S}_{\mathrm{n}}\right\}
\end{aligned}
$$

(8) 分别测算样本对象到 $S_{j}^{+}$和 $S_{j}^{-}$的欧式距离:

$$
\mathrm{D}_{\mathrm{i}}^{+}=\sqrt{\sum_{\mathrm{j}=1}^{\mathrm{n}}\left(\mathrm{S}_{\mathrm{j}}^{+}-\mathrm{S}_{\mathrm{j}}\right)^{2}} \quad \mathrm{D}_{\mathrm{i}}^{-}=\sqrt{\sum_{\mathrm{j}=1}^{\mathrm{n}}\left(\mathrm{S}_{\mathrm{j}}-\mathrm{S}_{\mathrm{j}}^{-}\right)^{2}}
$$

(9) 测算各样本对象与最优解的相对接近度 $\mathrm{C}_{\mathrm{i}}$ :

$$
\mathrm{C}_{\mathrm{i}}=\frac{\mathrm{D}_{\mathrm{i}}^{-}}{\mathrm{D}_{\mathrm{i}}^{+}+\mathrm{D}_{\mathrm{i}}^{-}}
$$

$\mathrm{C}_{\mathrm{i}}$ 越接近 1 , 表示评价对象越接近最优评价水平。

本文以我国 30 个省级行政区作为研究样本（港 澳台、西藏除外)，测度我国 2009-2018 年省域包容 性绿色发展水平, 在探讨我国包容性绿色增长整体趋 势的同时, 研究各地区包容性绿色增长水平的异质性, 以此识别我国包容性绿色增长的时空分布特征, 测度 结果见表 1 。

\section{表 1 省际包容性绿色增长综合评分}

\begin{tabular}{c|c|c|c|c|c}
\hline & $\mathbf{2 0 0 9}$ & $\mathbf{2 0 1 2}$ & $\mathbf{2 0 1 4}$ & $\mathbf{2 0 1 6}$ & $\mathbf{2 0 1 8}$ \\
\hline 北京 & 0.675 & 0.717 & 0.723 & 0.721 & 0.692 \\
\hline 天津 & 0.404 & 0.438 & 0.471 & 0.473 & 0.463 \\
\hline 河北 & 0.187 & 0.204 & 0.198 & 0.197 & 0.214 \\
\hline 上海 & 0.581 & 0.554 & 0.545 & 0.563 & 0.579 \\
\hline 江苏 & 0.412 & 0.490 & 0.471 & 0.472 & 0.499 \\
\hline 浙江 & 0.411 & 0.450 & 0.444 & 0.450 & 0.491 \\
\hline 福建 & 0.242 & 0.259 & 0.257 & 0.267 & 0.293 \\
\hline 山东 & 0.269 & 0.295 & 0.304 & 0.305 & 0.308 \\
\hline 广东 & 0.415 & 0.426 & 0.401 & 0.431 & 0.543 \\
\hline 海南 & 0.296 & 0.214 & 0.1948 & 0.239 & 0.252 \\
\hline 山西 & 0.178 & 0.178 & 0.185 & 0.183 & 0.227 \\
\hline 安徽 & 0.166 & 0.206 & 0.211 & 0.214 & 0.239 \\
\hline 江西 & 0.152 & 0.177 & 0.167 & 0.188 & 0.235 \\
\hline 河南 & 0.177 & 0.187 & 0.194 & 0.199 & 0.210 \\
\hline 湖北 & 0.194 & 0.214 & 0.235 & 0.250 & 0.256 \\
\hline 湖南 & 0.185 & 0.193 & 0.200 & 0.208 & 0.227 \\
\hline 内蒙古 & 0.165 & 0.204 & 0.232 & 0.228 & 0.215 \\
\hline 广西 & 0.140 & 0.137 & 0.129 & 0.140 & 0.147 \\
\hline 四川 & 0.195 & 0.212 & 0.222 & 0.218 & 0.241 \\
\hline 重庆 & 0.205 & 0.234 & 0.244 & 0.259 & 0.276 \\
\hline 贵州 & 0.1107 & 0.112 & 0.117 & 0.133 & 0.141 \\
\hline 云南 & 0.132 & 0.147 & 0.145 & 0.149 & 0.149 \\
\hline 陕西 & 0.236 & 0.206 & 0.248 & 0.262 & 0.258 \\
\hline 甘肃 & 0.127 & 0.142 & 0.170 & 0.174 & 0.177 \\
\hline 青海 & 0.125 & 0.137 & 0.154 & 0.162 & 0.166 \\
\hline 宁夏 & 0.189 & 0.183 & 0.188 & 0.191 & 0.207 \\
\hline 新疆 & 0.184 & 0.178 & 0.193 & 0.186 & 0.180 \\
\hline 辽宁 & 0.234 & 0.244 & 0.260 & 0.301 & 0.320 \\
\hline 吉林 & 0.203 & 0.185 & 0.207 & 0.216 & 0.221 \\
\hline 黑龙江 & 0.175 & 0.182 & 0.244 & 0.197 & 0.204 \\
\hline & & & & & \\
\hline & & & & & \\
\hline
\end{tabular}

从测算结果来看, 我国各地区包容性绿色发展水 平继续保持稳定上升, 创新维和共享维在包容性绿色 发展中所占比重最大, 协调维与开放维的权重次之, 绿色维的权重在其中占比最小, 在一定程度上说明创 新水平是影响包容性绿色发展水平最主要因素。

我国省域包容性绿色增长指数具有以下特征: 第一, 经济强省的包容性绿色发展水平整体领先, 但 也有停滞不前或者降低的趋势, 这些省份主要来自东 部沿海地区, 其因一方面得益于较高的创新水平和共 享水平, 另一方面则受绿色水平下降制约; 第二, 经 济弱省的包容性绿色发展水平普遍落后, 但多数省份 表现出显著上升态势, 这些省份主要来自内陆地区, 原因为相关省份的各维度指数都偏低, 但总体表现为 波动上升趋势; 第三, 包容性绿色发展的省际差距明 显, 但总体是缩小态势。由此可见, 中国省际包容性 绿色增长的不平衡、不协调、不充分问题十分突出, 中西部和沿海地区之间的差距尤其显著, 通过研究明 确中国省际包容性绿色发展的影响因素显得愈发急 迫。

从各大区域的包容性绿色发展水平来看, 整体呈 现东部地区 $>$ 东北地区 $>$ 中部地区 $>$ 西部地区。 从各区域间包容性绿色发展水平的速率来看, 整体表 现为 “中部地区 >东北地区>西部地区 > 东部地区” 说明其他地区对东部地区存在一定程度的 “追赶效 应”。

另外, 从整体上看, 我国包容性绿色发展水平处 于两端的省份的变化较大, 而包容性绿色发展处于中 间水平的省份变化较小, 包容性绿色发展的内部结构 没有发生太大的变化。同时, 我国包容性绿色发展的 区域差异显著, 东部地区的包容性绿色发展水平整体 差异最大, 中部和西部次之, 东北地区位整体差异最 小。从近年发展状况来看, 各区域之间的差异日渐缩 小, 且随时间推移包容性绿色发展水平的区域内差异 表现出一定的阶段性特征。

\section{2 省域包容性绿色发展的空间分布}

包容性绿色发展是一个综合的概念, 必须从一定 时空范围内进行评价, 并且同一省份内各区域的包容 性绿色发展水平都具有相似的地域特征, 而不同省份 之间区位因素和驱动因素的不同造成包容性绿色发 展水平在我国地区分布上的差异。现从以下几个角度 分析省域包容性绿色发展的空间分布。

集聚度: 包容性绿色增长集聚度, 代表一个地区 相对于全国的包容性绿色发展水平, 由前文的包容性 绿色增长测度体系得出, 计作 $\mathrm{J}$ 。

基尼系数: 运用基尼系数测度中国 30 个省级行 政单位包容性绿色发展水平分布的不均衡程度, 基尼 系数的公式如下: 


$$
G=\frac{1}{2 n^{2} \bar{X}} \sum_{i}^{n} \sum_{j}^{n}\left|x_{i}-x_{j}\right|
$$

式中: $\mathrm{n}$ 代表省级行政单位个数, $\overline{\mathrm{X}}$ 代表全国各 省包容性绿色发展平均得分; $\mathrm{x}_{\mathrm{i}}$ 和 $\mathrm{x}_{\mathrm{j}}$ 为任意两省包容 性绿色发展密度。

空间统计分析：借助莫兰指数计算结果，可分析 各省包容性绿色发展是否存在空间溢出效应。莫兰指 数的计算公式为:

$$
\text { Moran's I }=\frac{\mathrm{n}}{\sum_{\mathrm{i}} \sum_{\mathrm{j}} \mathrm{w}_{\mathrm{ij}}} * \frac{\sum_{\mathrm{i}} \sum_{\mathrm{j}} \mathrm{w}_{\mathrm{ij}}\left(\mathrm{x}_{\mathrm{i}}-\overline{\mathrm{x}}\right)\left(\mathrm{x}_{\mathrm{j}}-\overline{\mathrm{x}}\right)}{\sum_{\mathrm{i}}\left(\mathrm{x}_{\mathrm{i}}-\overline{\mathrm{x}}\right)^{2}}
$$

式中: $n$ 为样本数量; $w_{i j}$ 为空间权重矩阵 $W$ 的 $(i, j)$ 元素。根据地理学第一定律, 本文中 $W$ 的构建选用 01 矩阵。 $\mathrm{x}_{\mathrm{i}}$ 和 $\mathrm{x}_{\mathrm{j}}$ 分别是空间单元 $\mathrm{i}$ 和 $\mathrm{j}$ 的观测值; $\overline{\mathrm{x}}$ 是 观测值的平均值。莫兰指数正值反映了空间正相关性, 负值则反映空间负相关性。若对空间权重矩阵进行行 标准化处理, 使得结果取值范围在 $[-1,1]$ 的区间内。

综合各方面研究, 省域包容性绿色发展的空间分 布具有以下特征:

\section{包容性绿色发展呈现出高度集中的空间分布格 局}

根据各省份的包容性绿色发展情况，将省级行政 单位划分为高水平发展地区 $(\mathrm{J} \geqslant 60)$ 、中高水平发展 地区 $50 \leqslant \mathrm{~J} \leqslant 60$ )、中等水平发展地区 $(40 \leqslant \mathrm{~J} \leqslant 50)$ 、 中低水平发展地区 $(20 \leqslant \mathrm{~J} \leqslant 40)$ 和低水平发展地区 $(\mathrm{J} \leqslant 20)$ 五个级别。近十年我国包容性绿色发展高 水平区高度集中在少量的省级行政单元上, 且分布于 主要沿海经济发达省份。在此期间, 山东省和辽宁省 包容性绿色发展由中低水平转变为中等水平, 广东包 容性绿色发展上升到中高水平, 这些变化的省份均来 自东部沿海地带, 如图 1。

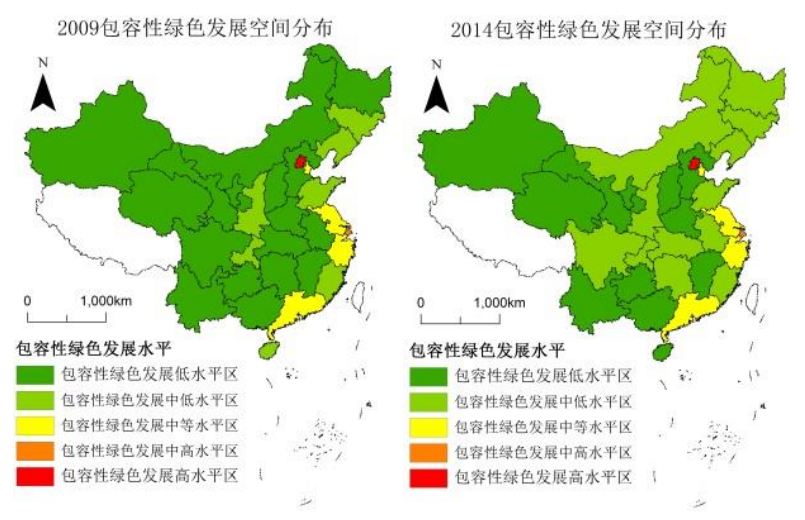

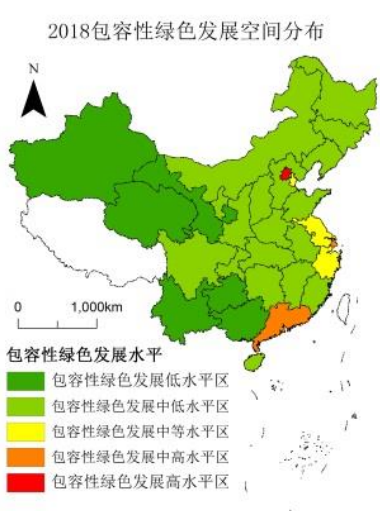

图 1 包容性绿色增长空间分布图

包容性绿色发展分布的不均衡趋势有所缓解, 分 布趋势由沿海向内陆扩散

包容性绿色发展水平在全国范围内呈现出不平 衡的分布特征, 近 10 年来该不平衡分布的趋势有所 缓解, 造成该现象的原因可能是经济机会和区域禀赋 长期以来在地区间分布的不均衡, 近年来国家不断强 调经济发展的持续性, 强调生产过程的绿色性, 发展 成果分配的公平性, 使得这种不均衡发展的格局已经 开始打破。

\section{长三角地区包容性绿色发展的空间溢出效应显 著}

国内各区域包容性绿色发展水平在空间上呈现 集聚分布模式，省级行政单位间的包容性绿色发展水 平存在空间溢出效应。这一效应显著发生在长三角地 区。一方面, 长三角拥有较高的经济发展水平和相应 的政策支持, 对包容性绿色发展有较强的推动作用; 另一方面, 长三角城市群内部一体化程度高, 城市职 能分工较明确, 在推动包容性绿色发展方面发挥了较 强的联合驱动作用。

\section{4. 结语}

包容性绿色发展是我国经济由高速增长转为高 质量增长的必然要求, 也是当前世界各国经济社会发 展的必然趋势。本文通过对我国包容性绿色发展水平 进行测度, 并通过地理视角对包容性绿色发展的区域 差异进行分析, 得出关于这一热点问题的一般结论, 以期为后续研究起到积极的推动作用。

\section{REFERENCES}

[1]Org Z. (2012) Inclusive Green Growth: The Pathway to Sustainable Development. World Bank.

[2]Bouma J, Berkhout E. (2015) Inclusive Green Growth, PBL Netherlands Environmental Assessment Agency. No.1708.

[3]Slingerland S. and Kessler J. (2015) Study on Public Private Partnerships For Contribution to Inclusive 
Green Growth, PBL Netherlands Environmental Assessment Agency.No.2557.

[4]Zhou Xiao-liang and $\mathrm{Wu}$ Wu-lin, (2018) The Measurement and Analysis of the Inclusive Green Growth in China, The Journal of Quantitative \& Technical Economics, 8:03-20.

[5]Zhou Xiao-liang and $\mathrm{Wu} \mathrm{Wu}$-lin. (2019) Inclusive Green Development: Theoretical Interpretation and Institutional Support System. Academic Monthly, $52: 41-54$

[6]Wang Yu-xin, Yu xing-hou and Huang Ling. (2019) Spatial Pattern Distribution and Evolution Characteristics of Inclusive Green Growth in Urban Areas of Yangtze River Economic Belt. Technology Economic, Vol38, No.6:80-89. 